\title{
Know versus Familiar: Differentiating states of awareness in others' subjective reports of recognition
}

\author{
Helen L. Williams \\ School of Psychology, Keele University, England \\ Chris J.A. Moulin \\ LEAD CNRS UMR 5022, Université de Bourgogne, France \\ \& Department of Experimental Psychology, University of Bristol, UK
}

Acknowledgments: This work derives from discussions at the ESRC-CNRS collaborative programme awarded to Moulin, (Recollection, Remembering and the Complex Nature of the Self; RES-170-25-0008). The data was collected at the University of Leeds for Williams's PhD, funded by a University Research Scholarship, and the manuscript was written while Williams held a Commonwealth Postdoctoral Fellowship at the University of Victoria funded by the Government of Canada. The authors thank Mike Masson for his advice on analysis.

Correspondence concerning this article should be addressed to Helen Williams, School of Psychology, Dorothy Hodgkin Building, Keele University, Staffordshire, ST5 5BG, UK. Email: helenwilliams098@gmail.com. Phone: +44 1782733664.

Full contact details for Chris Moulin: LEAD CNRS UMR 5022, Pole AAFE, Esplanade Erasme, Université de Bourgogne, 21065 DIJON, France. Email: christopher.moulin@ubourgogne.fr. Tel: +33 (0)3 80393968 . 


\begin{abstract}
In the Remember-Know paradigm whether a Know response is defined as a highconfidence state of certainty or a low-confidence state based on familiarity varies across researchers and can influence participants' responses. The current experiment was designed to explore differences between the states of Know and Familiar. Participants studied others' justification statements to 'Know' recognition decisions and separated them into two types. Crucially, participants were not provided definitions of Know and Familiar on which to sort the items - their judgments were based solely on the phenomenology described in the justifications. Participants' sorting decisions were shown to reliably map onto expert classification of Know and Familiar. Post-task questionnaire responses demonstrated that both the level of memory detail and confidence expressed in the justifications were central to how participants categorised the items. In sum, given no instructions to do so, participants classify Familiar and Know according to two dimensions: confidence and amount of information retrieved.
\end{abstract}

Keywords: Remember-Know, subjective experience, familiarity, dual-process, recognition.

Word count: 4320 (including abstract and footnotes) 
Dual-process accounts of recognition memory posit that recognition can be achieved through recollection of specific contextual information or evaluation of familiarity. Such a theory places emphasis on subjective experience, as in the Remember-Know (RK) paradigm where items are categorised as Remember when something that was thought or experienced at the time of encoding is retrieved and as Know without the recall of such associated information (Tulving, 1985). An unresolved issue is how Remember and Know responses map onto the processes of recollection and familiarity. While some view the states of Remembering and Knowing as orthogonal to the processes of recollection and familiarity (e.g., Gardiner, 2000; Wixted \& Mickes, 2010), many RK studies assume that the two categories map directly onto the two underlying processes (Migo, Mayes, \& Montaldi, 2012; Yonelinas, 2002). A related issue is whether other experiential states can be identified. Whilst the addition of a Guess response option is now common (Eldridge, Sarfatti, \& Knowlton, 2002; Gardiner, 2008), conceptualization of Know varies greatly across experiments and interpretation of Know responses has been called "the most vexatious problem in the remember/know paradigm" (Gardiner \& Richardson-Klavehn, 2000, p. 238). This problem is the focus of the current study.

The multi-dimensional nature of Know responses is evident from recognition justification statements. Gardiner, Ramponi, and Richardson-Klavehn (1998) analysed the content of 270 justifications of Remember, Know, and Guess responses. Compared to Remember justifications, Know justifications were shorter and were absent of contextual details; but included feelings of familiarity, 'just knowing', thinking a word occurred, or comments on the absence of details. In the current experiment, participants were presented with these Know justifications and their task was to examine differences within them ${ }^{1}$. 
The issue of whether Know responses contain contextual information has been investigated with source memory paradigms. Some studies have shown source retrieval for Know to only be at chance (e.g., Dewhurst \& Hitch, 1999; Dudukovic \& Knowlton, 2006) while other studies have shown source accuracy to be above chance for Know items (e.g., Meiser \& Sattler, 2007; Starns \& Hicks, 2005). Additionally, Meiser, Sattler, and Weißer (2008) demonstrated that while RK source accuracy can be equated in a quantitative way, there remains a qualitative difference whereby Remember retrieval involves more specific and integrated memory for episodic details than does Know retrieval. The variability in what is retrieved from memory when a Know response is made may be key to understanding the subjective experience and processes associated with that retrieval.

In the RK paradigm, how non-recollective experiences are defined to participants also varies. As shown in Table 1, some researchers include both familiarity and confidence within one response option, others emphasize either familiarity or confidence, and yet others ask participants to make Remember-Familiar judgments instead of Remember-Know - reasoning that there could be confusion between colloquial understanding of 'knowing' and its experimental definition. Geraci, McCabe and Guillory (2009) compared different Know definitions. When confidence was emphasised, Remember-Know judgments differed across words and non-words whereas SureUnsure judgments did not. However, when confidence was not emphasised in the Know definition, patterns were similar for Remember-Know and Sure-Unsure. Thus how subjective states are defined can have important implications for interpretation of RK responses, particularly with regard to the relationship between subjective experience and confidence.

[Table 1 about here] 
Using separate Know and Familiar response options, researchers have demonstrated different patterns of recognition for Know and Familiar items (Barber, Rajaram, \& Marsh, 2008; Conway, Gardiner, Perfect, Anderson, \& Cohen, 1997; Dewhurst, Conway, \& Brandt, 2009; Sauerland \& Sporer, 2009; Wright \& Sladden, 2003). These findings suggest that people can differentiate Remember, Know, Familiar, and Guess in memory tasks according to definitions provided by researchers and support the idea that more than one type of non-recollective subjective state of awareness could contribute to recognition (e.g., McCabe, Geraci, Boman, Sensenig, \& Rhodes, 2011). However, separation of Know and Familiar response options is not common and how people appreciate the differences between these experiential states is not known. We tested whether people can differentiate these experiential states when no definitions are provided.

Previously we gave participants definitions of Remember, Know, Familiar, and Guess and asked them to make judgments about the subjective experience and confidence expressed in others' justification statements (Williams, Conway, \& Moulin, 2013). We divided Gardiner et al.'s (1998) Know justifications into those that reflected a feeling of familiarity and those that reflected a feeling of knowing (based on the definitions provided in Table 2). Know justifications received higher confidence ratings than did Familiar justifications (Experiment 1); and when the intrinsic confidence expressed in the justification was manipulated, Know justifications were not consistently assigned to the Know category while assignment of Familiar justifications to Familiar was unaffected (Experiment 2).

[Table 2 about here]

The aim of the current experiment was to test whether non-experts could observe differences between statements reflecting a Know subjective experience and a Familiar subjective 
experience. Crucially, here participants were not asked to match the justification to a category based on experimental definitions, instead participants were simply asked to split the Gardiner et al. (1998) Know justifications into two types. This methodological change is key: previous research has either examined whether changes in definitions influence RK responses in a recognition task (Geraci et al., 2009), or has provided definitions of Know and Familiar for use when categorising others' justifications (Williams et al., 2013). However, Know and Familiar definitions may constrain responses - participants may merely assess the justifications in terms of how closely they match the provided definition. Our focus in the current experiment was on whether people can detect different experiential states simply from how these states are expressed in memory reports, without any constraints imposed by experimenter-written definitions.

Participants first sorted Know justification statements into two types. A subsequent questionnaire asked what criteria participants had based their categorisations on. Given that different information and epistemic feelings that come to mind during retrieval are associated with the subjective states of knowing and finding familiar, it was predicted that participants would be able to recognise those mnemonic processes in others' memory reports and identify different justifications that reflect different experiential states.

\section{Method}

\section{Participants}

Fifty psychology students (41 female) from the University of Leeds aged between 18 and 35 received participation credit for taking part. Participants were tested in groups of between two and ten. One participant's data were excluded for non-compliance with instructions. 


\section{Materials and procedure}

Stimuli were the 90 Know justification statements from Gardiner et al. (1998) ${ }^{2}$ where participants had categorised recognised items as Remember, Know, or Guess. Their definition of Know emphasizes both certainty, 'knew for a fact', and familiarity, 'familiar in the experimental context'. In previous research we had expertly categorised the Gardiner et al. justifications as either Familiar $(\mathrm{n}=43)$ or Know $(\mathrm{n}=47)$; inter-rater reliability $=.82$, see Williams et al. (2013).

Each cue word and its justification statement were printed on an individual card. Participants were instructed that: “...on a previous memory test participants had said yes, they recognised that cue word, and the justification on the card is the reason they gave for why they thought they recognised that cue word". Each participant received a set of cards and was instructed that we were interested in whether they could differentiate between two types of memory justification statement. Participants were instructed to read the statements and sort them into Type A and Type B along whatever criteria they thought the statements differed. Participants were instructed to place Type A cards in one pile and Type B cards in another pile, check that they were happy with their sorting decisions, and write 'Type A' or 'Type B' on each card. Participants then completed a questionnaire concerning what criteria they had used to make their sorting decisions.

\section{Results}

The relationship between expert and participant categorisation of items was calculated using the discrimination measure $d^{\prime}$ '. Since participants were not initially provided with definitions of Know and Familiar it was not known whether a participant considered Type A or Type B to map onto 'Know' (or 'Familiar'). Mapping was calculated based on each participant's majority response. For example, if the highest number of items a participant had grouped together was 
Know items, and they had labelled this pile 'Type A', then for this participant their label of Type A was assumed to map onto Know (and Type B was assumed to map onto Familiar). On the other hand, if the highest number of items a participant had grouped together was Familiar items, and they had labelled this pile 'Type A', then for this participant their label of Type A was assumed to map onto Familiar (and Type B was assumed to map onto Know).

Using majority mapping of Type A and Type B labels onto Know and Familiar definitions, mean $d$ ' was $.82(S D=.49)$, which was significantly above chance (zero), $t(48)=11.64, p<.001$, $d=1.67$, indicating that the association between expert and participant classification was reliable. In terms of the proportion of items this represents, $.65(S D=.10)$ of items participants categorised as Know were expert-classified Know items and $.67(S D=.12)$ of items participants categorised as Familiar were Familiar items, both significantly above chance $(.50)$, both $p$ 's $<.001, d$ 's $>1.41$. Participants separated the items into two categories that had a similar distribution of items to the expert categorisation of Know and Familiar.

As participants were not given any instruction regarding equal pile size, the size of the two piles differed across participants (Know items: $\min .=19$, $\max .=79$, mean $=55$. Familiar items: min. $=11, \max .=71$, mean $=35)$. Using $c$ as a measure of biased clustering, for participants who had a larger set of Know items $(\mathrm{n}=31$; Mean $c=-.66, S D=.33)$, proportion correct for Know $(M$ $=.60, S D=.05)$ was significantly lower than proportion correct for Familiar $(M=.69, S D=.13)$, $t(30)=4.93, p<.001, d=0.91$. For participants who had a larger set of Familiar items $(\mathrm{n}=10$; Mean $c=.48, S D=.30)$, proportion correct for Know $(M=.76, S D=.14)$ was significantly higher than proportion correct for Familiar $(M=.60, S D=.07), t(7)=6.00, p<.001, d=1.45$. For participants whose sets of Know and Familiar were approximately equal $(\mathrm{n}=8 ;$ Mean $c=-.02, S D$ $=.04)$, proportion correct for Know $(M=.70, S D=.09)$ was higher than proportion correct for 
Familiar $(M=.66, S D=.10)$; this difference was also significant, $t(9)=5.38, p=.001, d=0.42$, but was numerically much smaller than the differences shown by participants who had demonstrated biased clustering. Thus, for participants who showed a bias towards either Know or Familiar items, the proportion of items correctly categorised was higher for items in their smaller grouping. This suggests that participants' interpretations of what experiential states were expressed in these fewer items were more consistent, and these items were more similar (to each other), than those placed in the larger grouping. We suggest that perhaps participants trusted their interpretations more for the justifications that made up the smaller group, and that some of the items assigned to the 'other' category were items they were not sure how to interpret.

Finally participants completed a questionnaire about the criteria they had used to sort the items. Firstly, on a scale of -2 to +2 , participants rated the difficulty of sorting, how similar or dissimilar they found the statements, and whether they thought other people would sort the items in the same way as them. One-sample t-tests against the mid-point score of 0 showed that participants considered the items somewhat difficult to sort, $M=-0.67, S D=0.85, t(48)=5.54, p$ $<.001, d=-0.79$; thought the two types of statements were quite similar, $M=0.47, S D=0.94$, $t(48)=3.50, p=.001, d=0.50$; and considered it neither unlikely nor likely that others would sort the statements in the same way as them, $M=0.02, S D=0.95, t<1$.

Participants then saw a list of possible criteria on which they may have based their sorting decisions and selected those used. Except for 'gut instinct' and 'mainly guessing', criteria were phrased as comparisons, for example, 'more sure': I thought that for one Type of memory statement the people making the statements sounded more sure of their memories than for the other Type of memory statement. As shown in Table 3, the most common criterion endorsed was the above example of 'more sure'. Around $50 \%$ of participants also thought that for one type of 
statement people had 'recalled more information', a 'deeper level of processing', and/or shown more 'confidence' in their memory performance than the other type of statement. On average participants selected 3.63 criteria $(S D=1.27)$ from the list of $10(\min .=1$, $\max .=7)$.

[Table 3 about here]

Participants were next asked how confident they thought the people who had made the two types of statements had been and how much information/how many details the people had recalled. As 'confidence' and 'recalled more information' were two of the sorting criteria options, subsequent analyses examined whether ratings of confidence and detail for Know and Familiar items differed depending on endorsement of those criteria; see Figure 1. Separate 2(endorsement: yes/no) x 2(item type: Know/Familiar) ANOVAs were conducted with endorsement as a betweensubjects factor and item type as a within-subjects factor.

[Figure 1 about here]

For level of information/details, there was no main effect of endorsement, $F<1$, but a significant main effect of item type, $F(1,47)=4.39, p=.042, \eta_{\mathrm{p}}{ }^{2}=.085$, Familiar items were rated as containing more information/details than Know items. This was qualified by a significant interaction, $F(1,47)=4.39, p=.042, \eta_{\mathrm{p}}{ }^{2}=.085$. Participants who had not endorsed 'recalled more information' as a criterion did not rate Know and Familiar items as containing different levels of information/details, $t<1$. Participants who endorsed 'recalled more information' rated Familiar items as containing more information/details than Know items, $t(26)=2.84, p=.009, d=0.98$.

For confidence, there was no main effect of endorsement, $F<1$, and no main effect of item type, $F<1$. However, the interaction was significant, $F(1,47)=11.13, p=.002, \eta_{\mathrm{p}}{ }^{2}=.191$. Participants who endorsed confidence as a criterion rated Know items as expressing more confidence than Familiar items, $t(23)=2.55, p=.018, d=0.84$. Conversely, participants who had 
not endorsed confidence as a criterion rated Familiar items as more confident than Know items, $t(24)=2.14, p=.043, d=0.58$. The difference in ratings was larger for participants who had endorsed confidence as a sorting criterion ${ }^{3}$; see Figure 1.

\section{Discussion}

This experiment examined whether participants were able to identify two experiential states within what were all originally justification statements to recognised words assigned to Know. Participants' discrimination of Know and Familiar was reliably associated with expert categorisation. However, $d$ ' and the proportion of items that matched expert categorisation were not particularly high, demonstrating some divergence between participant and expert conceptualisation. Participants also rated the items as quite similar and somewhat difficult to sort. Although people have experience with interpreting their own memory-related experiential states, the stimuli used in this task were very short, very subjective in nature, and participants were not given any sorting instructions. Task novelty and subjectivity are reflected in the findings that participants considered it neither likely nor unlikely that others would sort the statements in the same way as them, and that participants used a variety of criteria to differentiate the statements. Discrimination patterns could suggest that at least some participants actually considered the justifications to all reflect one type of state of awareness; however, that the sorting decisions were reliable supports the conclusion that participants were able to discern differences in the mnestic properties of the statements.

Those participants who endorsed 'recalled more information' as a decision criterion rated Familiar items as containing more information than Know items. Without being instructed to use 'amount of information' as a sorting criteria, participants appear to have imputed similar differences in the statements and generated similar differentiation criteria as expert raters. That 
Familiar justifications were rated as containing more information/details than Know justifications fits with how these states are conceptualised. Our definitions separate an absence of recollection from an unsubstantiated feeling of familiarity (Table 2). Considering Know to be highconfidence-without-recollection indicates an absence of information in memory - the word (from the study list) is in memory, but no associated thoughts or images come to mind, and this absence is sometimes reported in the justifications. For example, Athlete "I am sure I saw it, but I can't remember why I think I saw it”. Based on this conceptualisation it follows that Know items should receive a low rating of how much information is in memory.

In contrast, in reporting an unsubstantiated feeling of familiarity, other possible reasons for why something feels familiar are often reported; for example, Keg "It was a feeling that it was there. I was not sure whether it was at work or here that I came across that word". Although the associated information mentioned does not help substantiate why the word feels familiar, its presence suggests that more has been retrieved from memory. That amount of information recalled was identified as a difference between items (at least by half the participants) suggests that Know and Familiar subjective experiences may reflect differences in what information is retrieved from memory.

As well as amount of information, confidence ratings also demonstrated an interaction with endorsement. In previous studies, Know responses have been associated with higher confidence than Familiar responses in recognition experiments (e.g., Dewhurst et al., 2009) and categorisation of others' subjective experiences (Williams et al., 2013). That participants who endorsed 'confidence' as a criterion rated Know items as more confident than Familiar items fits with these findings. However, participants who did not endorse confidence rated Familiar items as more confident than Know items. This result is difficult to interpret. It is possible that endorsement of 
'confidence' may have been influenced by the criterion wording: “...the participants who made those statements must have been more confident in their memory performance...". The word "performance" here could have implied that instead of confidence about the content of memory, this criterion reflected confidence about how well the person thought they were doing on the memory test.

The current findings do not support the single-process assertion that confidence is the sole driving force behind judgments of subjective experience (Dunn, 2008). If recognition memory was best understood in terms of a single underlying process of confidence or memory strength then ratings of confidence should have more clearly differentiated the stimuli in this task. Instead we have shown that participants used both confidence and amount of information/details reported in the justifications to differentiate the subjective experiences associated with Know and Familiar items ${ }^{4}$. Our findings fit with the recent continuous dual-process model proposed by Wixted and colleagues. As stated by Wixted and Mickes (2010): "The strength of memory and the content of memory are, in theory, separable and independent properties, but they often have been viewed as fundamentally incompatible ideas... the attempt to understand memory in terms of either strength or content is misplaced because both ideas are needed" (p. 1025). In their initial continuous-dual process model Wixted and Mickes (2010) assumed that high-confidence Know responses were mainly based on familiarity processes. However, a recent RK source-accuracy recall experiment led them to propose that high-confidence Know responses in recognition may be based on a recalllike process (Mickes, Seale-Carlisle, \& Wixted, 2013). This fits with the conceptualisation of Know responses as reflecting an experiential state of high-confidence-without-recollection employed here. With the separation of Remember, Know, Familiar, and Guess (RKFG) subjective experiences, both Remember and Know responses may result from a recollection-based retrieval 
process - Remember responses resulting from successful recollection and Know responses resulting from unsuccessful recollection. Meanwhile, Familiar and Guess responses may result from successful and unsuccessful familiarity-based processes respectively.

Some experiments have already utilised separate categories of Know and Familiar, however the majority of these studies examined learning of rich materials over a longer time period (Conway et al., 1997; Dewhurst et al., 2009; Herbert \& Burt, 2001, 2003, 2004). It could be argued that conceptualising Knowing as a feeling of high-confidence-without-recollection and Familiarity as an unsubstantiated feeling of familiarity might not apply to more basic recognition paradigms. However, Dewhurst et al.'s (2009) participants assigned 10\% of items to Know and $11 \%$ to Familiar at first test - a situation analogous to a single-time-point experiment. Although their rare word definition stimuli were more complex than the unrelated words typically used in recognition experiments, these patterns suggest that the separation of Know and Familiar might be applicable to the subjective experiences associated with retrieval of other materials.

One potential limitation to the study of states of awareness in memory is differences between experimenter and colloquial understanding of key terms. As shown in Table 1, some researchers exchange 'Know' for 'Familiar' because of potential confusion between experimental and colloquial understanding of 'know'. However, as highlighted by Hintzman (2011), 'familiar' is also not without problems "Familiarity is routinely invoked in formal and informal explanations of memory as though it were a concept with obvious meaning, but the term appears to mean more than one thing" (p. 259; emphasis in original); and even 'remember' can refer to a variety of memory processes in everyday life (e.g., Migo et al., 2012). McCabe and Geraci (2009) advocate the use of 'Type A' and 'Type B' instead of 'Remember' and 'Know' as this removes any preexisting connotations that participants may hold. However, with the separation of Know and 
Familiar responses (alongside Guess), use of neutral terminology (e.g., Type A/B/C/D) would not be advantageous as the participant would have to remember which letter referred to which experiential state. More importantly, use of neutral terminology may lead participants to interpret subjective states in a more linear (and therefore confidence-like) manner. Instead, we suggest that the experiences associated with $\mathrm{R} / \mathrm{K} / \mathrm{F} / \mathrm{G}$ responses are clearly defined to participants with examples and that manipulation checks are employed to ensure that participants have understood and used these categories correctly (Geraci et al., 2009; Migo et al., 2012). We consider that for researchers specifically interested in examining retrieval processes and/or experiential states, use of the four response options of $\mathrm{R} / \mathrm{K} / \mathrm{F} / \mathrm{G}$ will allow exploration of the complex and intricate relationships between source, confidence, and retrieval experiences. For researchers using an RK paradigm to examine retrieval processes in relation to a specific task or stimuli use of the four response options may not be necessary, but we suggest that all researchers be more precise in their terminology - using either a Know response defined as a state of high-confidence-withoutrecollection or a Familiar response defined as a feeling of familiarity - depending on the retrieval process that they are interested in.

In conclusion, this novel approach to understanding experiential states found that participants correctly classified approximately two-thirds of Know and Familiar items but reported finding the items similar and the task somewhat difficult. Although it may be more difficult to discern differences between Know and Familiar experiential states than, say, between these states and Remember, this does not mean that these subjective experiences should be encompassed in one response category. At the very least, we should conclude that, given that something has not been remembered or recollected, when reporting subjective experience two distinct factors come to mind - confidence and amount of information in memory. When participants had used these 
factors to differentiate items, confidence was higher for Know items, whereas Familiar items were reported to include more information. 


\section{References}

Barber, S. J., Rajaram, S., \& Marsh, E. J. (2008). Fact learning: How information accuracy, delay, and repeated testing change retention and retrieval experience. Memory, 16(8), 934-946.

Bastin, C., \& Van der Linden, M. (2003). The contribution of recollection and familiarity to recognition memory: A study of the effects of test format and aging. Neuropsychology, 17(1), 14-24.

Conway, M. A., Gardiner, J. M., Perfect, T. J., Anderson, S. J., \& Cohen, G. M. (1997). Changes in memory awareness during learning: The acquisition of knowledge by psychology undergraduates. Journal of Experimental Psychology: General, 126(4), 393-413.

Dewhurst, S. A., \& Anderson, S. J. (1999). Effects of exact and category repetition in true and false recognition memory. Memory \& Cognition, 27, 665-673.

Dewhurst, S. A., Conway, M. A., \& Brandt, K. R. (2009). Tracking the R-to-K shift: Changes in memory awareness across repeated tests. Applied Cognitive Psychology, 23(6), 849-858.

Dewhurst, S. A., \& Hitch, G. J. (1999). Cognitive effort and recollective experience in recognition memory. Memory, 7(2), 129-146.

Donaldson, W., MacKenzie, T. M., \& Underhill, C. F. (1996). A comparison of recollective memory and source monitoring. Psychonomic Bulletin \& Review, 3(4), 486-490.

Dudukovic, N. M., \& Knowlton, B. J. (2006). Remember-Know judgments and retrieval of contextual details. Acta Psychologica, 122(2), 160-173.

Dunn, J. C. (2008). The dimensionality of the remember-know task: A state-trace analysis. Psychological Review, 115(2), 426-446.

Eldridge, L. L., Sarfatti, S., \& Knowlton, B. J. (2002). The effect of testing procedure on remember-know judgments. Psychonomic Bulletin \& Review, 9(1), 139-145. 
Gardiner, J. M. (2000). On the objectivity of subjective experiences of autonoetic and noetic consciousness. In E. Tulving (Ed.), Memory, consciousness, and the brain: The Tallinn conference (pp. 159-172). Philadelphia: Psychology Press.

Gardiner, J. M. (2008). Remembering and knowing. In J. H. Byrne (Ed.), Learning and Memory: A Comprehensive Reference (pp. 285-305). Oxford: Elsevier Ltd.

Gardiner, J. M., \& Java, R. I. (1990). Recollective experience in word and nonword recognition. Memory \& Cognition, 18(1), 23-30.

Gardiner, J. M., Java, R. I., \& Richardson-Klavehn, A. (1996). How level of processing really influences awareness in recognition memory. Canadian Journal of Experimental Psychology, 50(1), 114-122.

Gardiner, J. M., Ramponi, C., \& Richardson-Klavehn, A. (1998). Experiences of remembering, knowing, and guessing. Consciousness and Cognition, 7(1), 1-26.

Gardiner, J. M., \& Richardson-Klavehn, A. (2000). Remembering and Knowing. In E. Tulving \& F. I. M. Craik (Eds.), The Oxford Handbook of Memory (pp. 229-244). New York: Oxford University Press.

Geraci, L., McCabe, D. P., \& Guillory, J. J. (2009). On interpreting the relationship between remember-know judgments and confidence: The role of instructions. Consciousness and Cognition, 18(3), 701-709.

Harlow, I. M., MacKenzie, G., \& Donaldson, D. I. (2010). Familiarity for associations? A test of the domain dichotomy theory. Journal of Experimental Psychology: Learning, Memory, and Cognition, 36(6), 1381-1388.

Herbert, D. M. B., \& Burt, J. S. (2001). Memory awareness and schematization: Learning in the university context. Applied Cognitive Psychology, 15(6), 617-637. 
Herbert, D. M. B., \& Burt, J. S. (2003). The effects of different review opportunities on schematisation of knowledge. Learning and Instruction, 13(1), 73-92.

Herbert, D. M. B., \& Burt, J. S. (2004). What do students remember? Episodic memory and the development of schematization. Applied Cognitive Psychology, 18(1), 77-88.

Hintzman, D. L. (2011). Research strategy in the study of memory: Fads, fallacies, and the search for the "coordinates of truth". Perspectives on Psychological Science, 6(3), 253-271.

Ingram, K. M., Mickes, L., \& Wixted, J. T. (2011). Recollection can be weak and familiarity can be strong. Journal of Experimental Psychology: Learning, Memory, and Cognition, 38(2), $325-339$.

Kelley, C. M., \& Jacoby, L. L. (1998). Subjective reports and process dissociation: Fluency, knowing, and feeling. Acta Psychologica, 98(2-3), 127-140.

McCabe, D. P., Geraci, L., Boman, J. K., Sensenig, A. E., \& Rhodes, M. G. (2011). On the validity of remember/know judgments: Evidence from think aloud protocols. Consciousness and Cognition, 20, 1625-1633.

McCabe, D. P., \& Geraci, L. D. (2009). The influence of instructions and terminology on the accuracy of remember-know judgments. Consciousness and Cognition, 18(2), 401-413.

Meiser, T., \& Sattler, C. (2007). Boundaries of the relation between conscious recollection and source memory for perceptual details. Consciousness and Cognition, 16(1), 189-210.

Meiser, T., Sattler, C., \& Weißer, K. (2008). Binding of multidimensional context information as a distinctive characteristic of remember judgments. Journal of Experimental Psychology: Learning, Memory, and Cognition, 34(1), 32-49. 
Mickes, L., Seale-Carlisle, T. M., \& Wixted, J. T. (2013). Rethinking familiarity: Remember/Know judgments in free recall. Journal of Memory and Language, 68(4), 333349.

Migo, E. M., Mayes, A. R., \& Montaldi, D. (2012). Measuring recollection and familiarity: Improving the remember/know procedure. Consciousness and Cognition, 21, 1435-1455.

Rajaram, S. (1993). Remembering and knowing: Two means of access to the personal past. Memory \& Cognition, 21(1), 89-102.

Sauerland, M., \& Sporer, S. L. (2009). Fast and confident: postdicting eyewitness identification accuracy in a field study. Journal of experimental psychology. Applied, 15(1), 46.

Starns, J. J., \& Hicks, J. L. (2005). Source dimensions are retrieved independently in multidimensional monitoring tasks. Journal of Experimental Psychology: Learning, Memory, and Cognition, 31(6), 1213-1220.

Tulving, E. (1985). Memory and consciousness. Canadian Psychology, 26(1), 1-12.

Williams, H. L., Conway, M. A., \& Moulin, C. J. A. (2013). Remembering and Knowing: Using another's subjective report to make inferences about memory strength and subjective experience. Consciousness and Cognition, 22, 572-588.

Wixted, J. T., \& Mickes, L. (2010). A continuous dual-process model of Remember/Know judgments. Psychological Review, 117(4), 1025-1054.

Wright, D. B., \& Sladden, B. (2003). An own gender bias and the importance of hair in face recognition. Acta Psychologica, 114(1), 101-114.

Yonelinas, A. P. (2002). The nature of recollection and familiarity: A review of 30 years of research. Journal of Memory and Language, 46(3), 441-517. 


\section{Table 1.}

Selected quotations detailing how non-recollective subjective experiences were described to participants. Labels show: A - definitions often referred to in the literature as 'standard definitions'; B - definitions that emphasize both familiarity and confidence; $\mathrm{C}$ - definitions that emphasize confidence; D - definitions that emphasize familiarity; E - justifications for using 'Familiar' instead of 'Know' as a response option.

\begin{tabular}{|c|c|c|c|}
\hline Label & Authors & $\begin{array}{l}\text { Response options } \\
\text { in experiment }\end{array}$ & $\begin{array}{l}\text { Representative quote and/or definitions provided to } \\
\text { participants }\end{array}$ \\
\hline A & $\begin{array}{l}\text { Gardiner and } \\
\text { Java (1990) }\end{array}$ & $\begin{array}{l}\text { Remember } \\
\text { Know }\end{array}$ & $\begin{array}{l}\text { "Often, when remembering a previous event or } \\
\text { occurrence, we consciously recollect and become } \\
\text { aware of aspects of the previous experience. At } \\
\text { other times, we simply know that something has } \\
\text { occurred before, but without being able consciously } \\
\text { to recollect anything about its occurrence or what } \\
\text { we experienced at the time." (p. } 25 \text {, emphasis in } \\
\text { original). }\end{array}$ \\
\hline $\mathrm{A}, \mathrm{C}$ & Rajaram (1993) & $\begin{array}{l}\text { Remember } \\
\text { Know }\end{array}$ & $\begin{array}{l}\text { "'Know' responses should be made when you } \\
\text { recognize that the word was in the study list but you } \\
\text { cannot consciously recollect anything about its } \\
\text { actual occurrence or what happened or what was } \\
\text { experienced at the time of its occurrence. In other } \\
\text { words, write 'K' (for 'know') when you are certain } \\
\text { of recognizing the words but these words fail to } \\
\text { evoke any specific conscious recollection from the } \\
\text { study list." (p. 102, emphasis added) }\end{array}$ \\
\hline $\mathrm{B}$ & $\begin{array}{l}\text { Bastin and Van } \\
\text { der Linden } \\
(2003)\end{array}$ & $\begin{array}{l}\text { Remember } \\
\text { Know } \\
\text { Guess }\end{array}$ & $\begin{array}{l}\text { “...classify a 'yes' response... as 'Know' if you do } \\
\text { not remember any information associated with the } \\
\text { face. You are sure that you have seen it because you } \\
\text { have a strong feeling of familiarity, but you do not } \\
\text { remember any information encoded with the face" } \\
\text { (p. } 24 \text {, emphasis added). }\end{array}$ \\
\hline B & $\begin{array}{l}\text { Gardiner, Java, } \\
\text { and Richardson- } \\
\text { Klavehn (1996) }\end{array}$ & $\begin{array}{l}\text { Remember } \\
\text { Know } \\
\text { Guess }\end{array}$ & $\begin{array}{l}\text { "The subjects were told that a know response meant } \\
\text { that they knew for a fact that the word occurred in } \\
\text { the study list, because the word was familiar in the } \\
\text { experimental context, but they did not recollect it's } \\
\text { occurrence" (p.116, emphasis added). }\end{array}$ \\
\hline
\end{tabular}




\begin{tabular}{|c|c|c|c|}
\hline B & $\begin{array}{l}\text { Kelley and } \\
\text { Jacoby (1998) }\end{array}$ & $\begin{array}{l}\text { Remember } \\
\text { Know }\end{array}$ & $\begin{array}{l}\text { "A Know response is defined as the inability to } \\
\text { recollect any details of the study presentation in } \\
\text { combination with a feeling of familiarity or } \\
\text { certainty that the word was studied" (p. 134, } \\
\text { emphasis added). }\end{array}$ \\
\hline $\mathrm{C}$ & $\begin{array}{l}\text { Geraci, McCabe, } \\
\text { and Guillory } \\
(2009)\end{array}$ & $\begin{array}{l}\text { Remember } \\
\text { Know }\end{array}$ & $\begin{array}{l}\text { Experiment 1, confidence emphasized: "You should } \\
\text { make a know judgment if you recognize the item } \\
\text { from the study list, but you cannot consciously } \\
\text { recollect anything about its actual occurrence or } \\
\text { what happened or what was experienced at the time } \\
\text { of its occurrence. In other words, write 'know' when } \\
\text { you are certain that you recognize the item, but it } \\
\text { fails to evoke any specific conscious recollection } \\
\text { from the study list." (p. } 707 \text {, emphasis added). } \\
\text { Experiment } 2 \text {, confidence not emphasized: "You } \\
\text { should respond know, by writing 'know' on the } \\
\text { blank, if you think the item was studied but you } \\
\text { cannot recollect any details about the study event." } \\
\text { (p.708) }\end{array}$ \\
\hline $\mathrm{D}$ & $\begin{array}{l}\text { Dewhurst \& } \\
\text { Anderson (1999) }\end{array}$ & $\begin{array}{l}\text { Remember } \\
\text { Know } \\
\text { Guess }\end{array}$ & $\begin{array}{l}\text { "A know response is one in which you recognize the } \\
\text { item because it feels familiar in this context, but you } \\
\text { cannot recall its actual occurrence in the earlier } \\
\text { phase of the experiment. You recognize the item } \\
\text { purely on the basis of a feeling of familiarity" (p. } \\
667 \text {, emphasis added) }\end{array}$ \\
\hline $\mathrm{E}$ & $\begin{array}{l}\text { Donaldson, } \\
\text { MacKenzie, and } \\
\text { Underhill (1996) }\end{array}$ & $\begin{array}{l}\text { Remember } \\
\text { Familiar }\end{array}$ & $\begin{array}{l}\text { "...familiar rather than know was used to indicate } \\
\text { nonrecollection, because the word know carries a } \\
\text { connotation of certainty that is inconsistent with a } \\
\text { confidence rating that indicates lack of certainty. } \\
\text { Participants find it hard to say that they are unsure } \\
\text { that an item was there but that they know it was" (p. } \\
\text { 487, emphasis in original). }\end{array}$ \\
\hline $\mathrm{E}$ & $\begin{array}{l}\text { Harlow, } \\
\text { MacKenzie, and } \\
\text { Donaldson (2010) }\end{array}$ & $\begin{array}{l}\text { Recollect } \\
\text { Familiar }\end{array}$ & $\begin{array}{l}\text { "Participants are trained to distinguish between } \\
\text { familiarity and recollection (rather than the } \\
\text { potentially misleading terms knowing and } \\
\text { remembering)" (p. 1385, emphasis in original). }\end{array}$ \\
\hline $\mathrm{E}$ & $\begin{array}{l}\text { Ingram, Mickes, } \\
\text { and Wixted } \\
(2011)\end{array}$ & $\begin{array}{l}\text { Remember } \\
\text { Familiar }\end{array}$ & $\begin{array}{l}\text { "...we exchanged know with familiar in an attempt } \\
\text { to reduce confusion between the colloquial and } \\
\text { experimental use of know" (p. 328; emphasis in } \\
\text { original). }\end{array}$ \\
\hline
\end{tabular}




\section{Table 2.}

Definitions of Knowing and Familiarity provided to participants at the end of the decision criteria questionnaire (left) and example stimuli statements (right). For the definitions the instructions to participants were: "Below are two definitions that are typically provided to participants in memory experiments. Participants would use these statements after they had responded YES - they did think a particular item had been on the list of items they had had to learn. We are interested in whether these definitions fit with your definitions of Type A and Type B memory statements?" Participants identified which of their item types (A or B) fit with each definition (Know or Familiar).

Subjective Experience

Know

Familiar

\section{Definition}

For this item you simply Know that the item was on the previous list without any of the other feelings associated with vividly remembering that you have seen the item before. For example, if you see someone on the street you may think 'who is that? Oh yes, it's my friend Rob, I know him really well...'

For this item you have a feeling of Familiarity with the item and because of that you think that the item was on the previous list. For example, if you see someone on the street you may think 'who is that? They look very familiar... I don't know where I know them from but they are definitely familiar... ,"
Example Stimuli

Hotel: It is one of the words I thought it was there yesterday, but there was no particular reason...

Sea: It looked sort of as if I saw it, but there was nothing associated to it.

Nun: I could not remember the situation but I knew I saw the word somewhere.

Paper: It was as if I had seen it, I am sure it was there yesterday, but I cannot remember seeing it.

Professor: It was not in any of the little stories I made up to remember the words, but I had a strong feeling of familiarity.

Butterfly: It was one of those words that rang a bell.

Rectangle: I think I saw this word (but maybe it was triangle!), I do not remember visualising a rectangle but I saw it.

Library: I think it came back to me but I cannot pinpoint actually seeing it. 


\section{Table 3.}

Decision criteria for statement sorting and the percentage of participants who endorsed each criterion.

Decision criterion

Percentage of participants who endorsed

More sure

$67.3 \%$

Recalled more information

$55.1 \%$

Deeper level of processing

$53.1 \%$

Confidence in memory performance

$49.0 \%$

Visual imagery

$40.8 \%$

Concrete words

$36.7 \%$

Emotional language

$26.5 \%$

Gut instinct

$14.3 \%$

Abstract words

$12.2 \%$

Mainly guessing

$8.2 \%$ 


\section{Figure Captions:}

\section{Figure 1.}

Mean ratings of level of information/amount of details recalled (A) and confidence in memory performance (B) split by whether the participant had endorsed 'recalled more information' or 'confidence' as decision criteria. Error bars show 1 standard error of the mean. 
DIFFERENTIATING KNOWING AND FAMILIARITY USING A SORTING TASK 26

\section{Footnotes}

${ }^{1}$ We are grateful for John Gardiner's permission to use these stimuli.

${ }^{2}$ As one of Gardiner et al.'s (1998) participants did not provide two Know justifications, one Know statement was duplicated and included twice: Bluebell "I am sure about that one, there were a couple of words which were similar and were part of the category flower".

${ }^{3}$ A corresponding ANOVA comparing confidence ratings given to Know and Familiar justifications by participants who had or had not endorsed 'more sure' did not demonstrate significant main effects of endorsement or justification type and no significant interaction (all $p>$ .25). Although the means showed the same pattern as the ANOVA split by 'confidence', for 'more sure' only 16 participants had not endorsed this criterion resulting in uneven group sizes for ANOVA.

${ }^{4}$ Around $50 \%$ of participants also endorsed 'more sure' and 'deeper level of processing' as sorting criteria. Although no follow-up questionnaire items examined these criteria, in line with our previous findings (Williams et al., 2013), endorsement of these criteria shows that when asked about the nature of others' recognition memory, people use a variety of factors to differentiate categories of subjective experience. 